\title{
Reality Play: Documentary Computer Games Beyond Fact and Fiction
}

\author{
Joost Raessens \\ Utrecht University
}

\begin{abstract}
Computer games such as JFK Reloaded and 9-11 Survivor not only aim at an accurate documentation of particular events - such as the assassination of John F. Kennedy and the Twin Towers attack-but also at the playful re-enactment of these traumatic events. In this article, I discuss whether the phrase "documentary computer games" is useful in defining these games. These "docu-games" try to combine the facts of documentaries and the fiction of computer games-elements that seem hard to reconcile at first sight. Do these games create a harmonious "space of communication" in which feelings of mutual understanding occur between designers and players?
\end{abstract}

Truth is never easily come by. Like Don Quixote, we can be perplexed by the intertwining of the credible and the fantastic.

Rodney Bolt, History Play

Exactly 41 years after John F. Kennedy (JFK) was assassinated in Dallas in 1963, the Scottish company Traffic Games released the computer game JFK Reloaded on November 22, 2004. ${ }^{1}$ The objective of the game is to enable players to adopt the position of Lee Harvey Oswald, killing JFK with three bullets. Players earn points if they succeed in matching their shots with the official version of the events as described by the Warren Commission. Established by Lyndon B. Johnson, the Warren Commission investigated the assassination, and in 1964 presented its single bullet theory, or, as conspiracy theorists prefer to call it, the magic bullet theory. According to this theory, a single bullet fired by Oswald caused seven injuries to

Correspondence should be addressed to Joost Raessens, Faculty of Arts, Institute for Media and Re/presentation, Utrecht University, Kromme Nieuwegracht 29, 3512 HD Utrecht, The Netherlands. E-mail: joost.raessens@let.uu.nl

${ }^{1}$ I use the term "computer games" broadly and do not distinguish between the different available platforms. 
the bodies of JFK and Governor John Connally from Texas—even for experienced players certainly not an easy task to perform.

Although the Kennedy family apparently called the game "despicable," the developers defended JFK Reloaded by arguing that those players who succeeded in realizing the goal of the game reinforced the truth of the most important conclusion of the Warren Commission: There was no conspiracy, and Oswald acted alone. This lone gunman theory contradicts approximately $75 \%$ of Americans whose opinions were strengthened by Oliver Stone's movie, JFK (1991), in their conviction that some kind of conspiracy existed. According to the director of Traffic Games, Kirk Ewing (n.d.), JFK Reloaded wrote "documentary history" by using game technology to enable people to reenact the assassination in an interactive way. This educational docu-game, as Traffic Games characterized it, is said to combine elements of the documentary and the computer game by enabling the player to recreate this historical event in an interactive way, without the spectacle and the fiction of Stone's movie. ${ }^{2}$

When analyzing the ways in which players discussed this game on the Water Cooler Games forum, three types of reactions can be discerned. ${ }^{3}$ The players who stated that the assassination of JFK "has been such a big historical controversy, a simulation seems like an instructive way to understand it," surrender to the simulation by taking it at interface value. On the other hand, those players who stated, "it seems ridiculous that a simulation could concretely prove anything" and discharge the game as "some programmers using an event in history to make some cash," are denying the game's importance. Players who argued, "the developers claim they believe Oswald acted alone, they built the game to favour this assumption," are discussing the game's built-in assumptions. Although several commentators criticized Traffic Games for "selling" the game as an educational aide only, the discussion shows that users appropriated this commercial game for what Turkle (1996) called "consciousness-raising" (p. 71).

\footnotetext{
${ }^{2}$ On the Water Cooler Games forum, Ian Bogost described this game as follows: "It's very ... antiseptic, let's say, very scientific. There is little attempt to create a sense of reward or pleasure in the violence. The player is very focused on the ballistics and the timing" (see www.watercoolergames.org/archives/000295.shtml).

${ }^{3}$ These reactions resemble the three possible answers Sherry Turkle (1996) had to "the seduction of simulation" (p. 71). According to Turkle, players can surrender to the seduction (simulation resignation), reject it (simulation denial), or learn to deconstruct the assumptions that are built into the simulation (simulation understanding). This last option is the one Turkle seemed to favor. The game was distributed via www.jfkreloaded.com. These reactions can be found at the forum of Water Cooler Games (see Note 2). Although JFK Reloaded is a simulation with persuasive motives, it contains textual and contextual indications that we must switch to what Roger Odin (1995b) called "a documentarizing lecture" (p. 234). Computer game-based political messaging as Tax Invaders (see the article by Ian Bogost, this issue), does not contain these kinds of indications.
} 


\section{DOCUMENTARY COMPUTER GAMES}

Contemporary computer games not only simulate events from which people have a certain distance, such as the assassination of JFK, but also more recent events for which precise impact is hard to decipher now, such as the attack on the Twin Towers. They are called "documentary computer games" because they attempt to document such traumatic events in a historically correct way as well as playfully reenacting them. These docu-games are part of so-called serious games, games used in areas such as education, training, and politics that go beyond mere entertainment purposes. Because these games are in different degrees based on actual news events, they also may be referred to as "news gaming." ${ }^{4}$ In this article I investigate to what extent and in which ways computer games can be viewed as a documentary medium. ${ }^{5}$

In most cases, documentary computer games are developed by collectives of game developers, artists, and political activists who use games to foreground social and political issues. Computer game technology offers a new generation of artists accessible tools to either entirely create new games from scratch or develop modifications of existing commercial releases - turning a platform for pure fantasy into a medium for social realism and critique. ${ }^{6}$ Whether the commercial game industry is focused on the production of fictional worlds (e.g., Grand Theft Auto [Rockstar Games, 2004] and The Sims [Electronic Arts, 2000]) or on realistic reconstructions of real life (think of sports games, e.g., FIFA 06 [Electronic Arts, 2006]), the pursuit of historical accuracy is explicitly subservient to entertainment value. Docu-games on the other hand, strive for "facticity" or "documentarity" to expose players to events and places that would remain inaccessible to them otherwise. ${ }^{7}$

Mainstream games, such as Grand Theft Auto and FIFA 06, are based on fictional or realistic scenarios in which the intensity of feeling and the reflexivity of

\footnotetext{
${ }^{4}$ See www.newsgaming.com. Gonzalo Frasca's own games Madrid and September 12th deal with the 3/11 terrorist attacks in Spain and the War on Terror. Other games in this category are 9-11 Survivor, Waco Resurrection, and Escape from Woomera-games I discuss in this article. Kuma War is referred to as a "reality game" that offers "playable re-creations of real war events released weeks after they occur" (see www.kumawar.com).

${ }^{5}$ On November 30th, 2005, the International Documentary Festival Amsterdam in cooperation with Mediamatic (www.mediamatic.nl), organized an evening program about computer games as a documentary medium. Speakers were Brody Condon, Julian Oliver, Michael Lew, and myself. For more information, see www.idfa.com.

${ }^{6}$ The questions I raise in this article are related to those of Alexander R. Galloway (2004) and Gonzalo Frasca (2004) who analyzed the possibilities of computer games to deal with social realism (Galloway) and social and political issues (Frasca). Although Galloway took traditional theories of realism as his point of departure, Frasca's explorations were mainly based on the work of drama theorist Augusto Boal. My own perspective is that of the discourse on documentary.

${ }^{7}$ To fall within my definition of a documentary game, simulations have to contain textual and contextual indications that we must switch to a "documentarizing lecture," such as the actual events the games I
} 
thought are, in the end, subordinated to the actuality and causality of action (Kattenbelt \& Raessens, 2003). Docu-games, on the other hand, try to break through the dominance of action to do justice to the complexity of experience: feeling, reflexivity, and action in their mutual relation. As I explain more in detail next, special attention is paid to the intensity of feeling in 9-11 Survivor (Kinematic, 2003), and to reflection and critical thinking in Escape from Woomera (2003). The fact that these docu-games immerse players in the reality of the game while offering them all kinds of possibilities to participate (see Raessens, 2005), for example in making choices with moral implications, transforms play into a meaningful, interactive experience.

Before engaging in the theoretical discussion about the documentary status of computer games in more detail, I present three further examples of computer games that are considered documentaries in one way or another. ${ }^{8}$

\section{9-11 Survivor (2003)}

One of the artists involved in the development of docu-games is Brody Condon, who also teaches game design in Los Angeles. Condon supervised the game design class that produced 9-11 Survivor and was a member of the art collective C-level from Los Angeles that was responsible for the production of Endgames: Waco Resurrection (C-level, 2003).

In 9-11 Survivor, which was briefly available on the Internet in 2003, the player is trapped in the burning Twin Towers on September 11, 2001. In one scenario the player is a businessman unable to find an escape route. The only choice the player has is to perish by fire or plunge to death. In other scenarios, the player is able to escape because he or she is situated on one of the lower floors of the building, he or she has a gas mask available, or a few brave firefighters come to the rescue.

The three students, John Brennan, Mike Caloud, and Jeff Cole, who formed the art collective Kinematic that was responsible for this game, received death threats and were publicly condemned for bad taste and moral indecency. They were accused of exploiting this tragedy commercially. However, it was never their intention to release a commercial version of this game, and therefore, this accusation

discuss in this article are based on. As Odin (1995b) wrote, "a documentary will have a higher degree of "documentarity"' (p. 229) the more it blocks operations that constitute the process of fictionalization. In $J F K$ Reloaded, for example, the freedom to produce a story is blocked to a large degree. Being a docu-game, it would be impossible for Oswald not to aim at killing JFK. Games such as The Sims and Food Force, which are based on more abstract (but nonfantastic) events, do not block the production of a story in this way. Furthermore, the fact that the Food Force Web site (www.food-force.com) differentiates between "the game" and "the reality" is a contextual indication that favors a "fictionalizing" lecture of the game over a "documentarizing" one.

${ }^{8}$ For more information on the work of Brody Condon, see www.tmpspace.com. For information on 9-11 Survivor, see www.selectparks.net/911survivor. For information on Escape from Woomera, see www.escapefromwoomera.org. 
seems an untenable one. The goal of the game was to immerse the player in the terrifying surroundings of the burning towers and to let him or her experience how it must have felt to be trapped inside. The interactivity of the game, and the realistic nature of the design of the Twin Towers, enabled them to emphasize the immediacy of this frightening moment. This kind of immediacy was lost in the desensitization produced by the constant repetition of these images at CNN. A few months after its release, Kinematic withdrew the game from the Internet-not because of its controversial reception, but because the collective received an $\$ 8,000$ bill for heavy site traffic.

\section{Endgames: Waco Resurrection (2003)}

This game from C-level is a reality-based, role-playing game in which four players assume the role of the cult leader David Koresh at his virtually reconstructed compound in Waco, TX. Koresh, head of a religious sect called the Branch Davidians, was killed when the FBI burst into his compound on February 29th, 1993 - an attack that took the lives of 85 members of the sect. According to C-level, this game is an interactive documentary that pays much attention to historic details. The designers of the game used authentic images made during the attack and sound recordings of David Koresh himself.

The players wear hard plastic masks with built-in microphones that function as interface. Assuming the role of Koresh, the four players run around the compound, shooting at FBI agents and other opponents. The game was released in 2003, which was 10 years after the event. According to C- Level, Koresh is the paradoxical personification of the political landscape of the United States: He is both the besieged and assaulted "other" as well as a logical continuation of the neo-conservative political vision. Players experience this paradoxical situation when adopting the role of Koresh.

\section{Escape from Woomera (2003)}

In 1998 Julian Oliver founded Selectparks, a collective of game developers, artists, and political activists, in Melbourne, Australia. This collective used games as a political, documentary medium. In Escape from Woomera, designed by Julian Oliver and two of his friends, players are invited to adopt the character of an asylum seeker who is imprisoned in an immigration detention center while his application for asylum is under consideration. By immersing themselves interactively in this world, which otherwise would be completely hidden from view, and living through the experiences, gamers gain an insight into the miserable living conditions of these asylum seekers. Players are challenged to escape by using the means available to them, such as digging tunnels, scaling fences, or using the legal help of sympathetic lawyers. 
The designers of Escape from Woomera also received a hostile reception for using the medium of the computer game for a serious discussion of a human rights issue in Australia. They based their game on extensive documentary research, revealing that the Australian government had been withholding information about the inhuman conditions of immigration detention centers such as Woomera. Remarkably enough, the game was co-financed by the Australia Council for the Arts. Phillip Ruddock, then Immigration Minister, was not amused by this contribution of $\$ 25,000$ (Australian) to a game that in his opinion pushed players into what he called "unlawful behavior." The Woomera Detention Center was closed in April 2003.

\section{FACT OR FICTION?}

The creators of the computer games mentioned previously claim that they are documentary, but at first sight this claim seems far from convincing. The arguments that have been used to criticize the documentary film (see Kessler, 1998) also seem to apply to the medium of the computer game.

According to the first of these three arguments, the documentary can never live up to its traditional claim of representing reality objectively. As Michael Renov (1993a) argued, "nonfiction contains any number of 'fictive' elements, moments at which a presumably objective representation of the world encounters the necessity of creative intervention" (p. 2). Due to the presence of the movie camera, which influences the filmed object, and through the use of framing, editing, narration, musical accompaniment, characters, and voiceover, a documentary creates its own object and by doing so, its own "truth." As a discursive form, documentary "constitutes the objects which it pretends only to describe realistically and to analyze objectively" (Renov, 1993a, p. 7). When applying this argument to so-called documentary computer games, we have to conclude that even when these games succeed in being more or less historically accurate, they always occupy a comparable tense position between fact and fiction. ${ }^{9}$

The second argument is concerned with the possibilities of digital manipulation. The arrival of the digital image has seriously undermined the idea that the photographic image, considered to be an indexical sign, has the status of scientific evidence. The discourse of photography has traditionally been called on to legitimatize the documentary film; hence, the reduction of the indexical status of the photographic image causes the documentary to lose its legitimization. When comparing the views of two authors who have been crucial in this debate, we immedi-

\footnotetext{
${ }^{9}$ As Renov (1993a) wrote, "the common bonds between fiction and nonfiction may be illuminated with concepts drawn from historiography, postmodernist theory, and philosophy" (p. 4). Referring to the work of the Italian postmodern philosopher Gianni Vattimo, I further elaborate on this issue in Raessens (2005).
} 
ately grasp the impact of the process of digitization. On one hand, in his work, “The Ontology of the Photographic Image," André Bazin (1967) defined the photographic image as follows: "The photographic image is the object itself, the object freed from the conditions of time and space that govern it" (p. 14). Brian Winston (1993), on the other hand, defined the impact of digital retouching technology as follows: "In the longer term, this leaves the documentary film project in all its guises in parlous state" (p. 56). Two years later, he wrote: "These technological developments ... will have a profound and perhaps fatal impact on the documentary film. It is not hard to imagine that every documentarist will shortly (that is, in the next fifty years) have to hand, in the form of a desktop personal video-image-manipulating computer, the wherewithal for complete fakery. What can or will be left of the relationship between image and reality?" (p. 6). Because computer games are at best simulations of reality, as they are not composed of photochemically produced images but of computer generated images, they would hence lack every kind of legitimization to a documentary status.

The third argument is not from media theory, but from traditional historical theory. Historians who are inspired by the 19th century German historian Leopold von Ranke think that the writing of history comes down to saying "what really happened." They "see their profession as objective, accretive, and teleologically governed as each generation of scholarship refines the truth and attributes additional data" (Uricchio, 2005, p. 336). Their basic assumption - that there are stable, fixed historical facts that the historian reveals-is inconsistent with one of the most distinguishing characteristics of computer games: interactivity. As William Uricchio argued, "the interaction between a present-day player and the representation of a historically specific world seems to challenge any notion of a unique configuration of historical 'fact' and 'fixity,' giving way instead to the historically inconsistent and ludic" (p. 327). Thanks to interactivity, players are in the position to organize their own text in a playful manner and thereby construct their own meanings of the game.

\section{DOCUMENTATION}

On the basis of these three arguments, we might be tempted to conclude that computer games cannot be used for historical documentation. ${ }^{10}$ However, these three arguments are themselves open to criticism.

As for the first argument, the documentary was never exclusively seen as a reproduction of objective reality resulting automatically from the very nature of the

\footnotetext{
${ }^{10}$ According to Noël Carroll (1996), these arguments against the non-fiction film are a form of postmodernist skepticism. He wanted to refute what he took to be "overly facile skepticism about the possibility of making motion pictures that are genuinely in the service of knowledge" (p. 285).
} 
cinematographic apparatus. When the father of modern documentary, John Grierson, used the term "documentary" in the mid-20s to label the non-fiction films made by Robert J. Flaherty (e.g., Nanook of the North, 1922, and Moana, 1926), he stated that the documentary must be seen as a "creative treatment of actuality." 11 Even though this formulation lacks clarity about the specific relation between the actuality part—as a form of evidence — and the creative treatment part—as a form of manipulation —it does make clear that the documentary form is, as Renov pointed (1993a) out, "the more or less artful reshaping of the historical world" (p. 11). Because the computer games mentioned previously treat actuality in a creative way, Griersons' paradoxical definition allows us to consider these games as a form of documentary.

The second argument also is open to an important objection. There has been a shift in focus in the field of documentary theory in the 1980s. In describing documentary films, we no longer focus exclusively or primarily on the defining characteristics of the documentary image; for example, its indexical status. ${ }^{12}$ The semio-pragmatic dimension of documentary film has become far more important, referring to the ways in which spectators or users are part of the structure and meaning of films that they treat as documentaries. According to the French semio- pragmatist Roger Odin (1995b, p. 234), individual spectators are able to produce a "documentarizing lecture" of each film — even a fictional film. If I watch, for example, Hitchcock's (1958) Vertigo because I wish to find out which hotel room is Judy Barton's (Kim Novak) at the moment Scottie (James Stewart) discovers her- because I am a Hitchcock fan wishing to rent this room for a night ${ }^{13}$ - I exchange a "fictionalizing" lecture for a "documentarizing" one, even for a brief moment. According to Odin, films that we usually call "documentary" do not only contain textual but also contextual information that indicates that we must switch to such a documentarizing lecture. ${ }^{14}$ Scientific animation films such as the BBC documentary Walking with Dinosaurs (broad-

\footnotetext{
${ }^{11}$ For the history of the word "documentary," see Winston (1995, pp. 11-14). According to the Internet Movie Database (http://www.amazon.imdb.com/title/tt0017162/trivia), "the word "documentary' was first applied to films of this nature in an anonymous review of the movie [Moana] written by John Grierson, a.k.a. 'The Moviegoer,' in New York Sun, 8 February 1926."

${ }^{12}$ Galloway (2004) asked the same question: "Is social realism even possible in the medium of the videogame where each pixel is artificially created by the machine?" From the semio-pragmatic perspective I present in this article, it is possible to answer this question affirmatively.

${ }^{13}$ It is Room 401 of the York Hotel, San Francisco. In Vertigo: The Making of a Hitchcock Classic Dan Auiler (1998) referred incorrectly to Room 501—probably because the York Hotel promotes this room as the Vertigo Room.

${ }^{14}$ According to Odin (1995a), "any reading of an image consists of 'applying' to it processes that are essentially external to it. This reading does not result from an internal constraint, but from a cultural constraint" (p. 213). The fact that the International Documentary Festival Amsterdam organized a program about documentary computer games (see Footnote 5) can, for example, be considered as such a cultural constraint. Participants in this program are more likely to give a documentarizing lecture than those who play the games in another context.
} 
cast in 1999) also may initiate such a documentarizing lecture. ${ }^{15}$ The games mentioned previously contain historically accurate images in which the status as documentaries is explicitly established in a specific cultural space; that is on the accompanying Web sites and in interviews. Thus, they contain textual and contextual instructions that stimulate such a documentarizing lecture. ${ }^{16}$

Finally, the third argument equally invites criticism. The Rankean idea that writing history is saying "what really happened" can be situated at one of the extreme ends of the spectrum of historical theory. At the other end of the spectrum, we find poststructuralist historiography, "charged by its critics with upsetting the applecart of the historical trade by challenging notions of facticity, explanatory hierarchies, master narratives, and ... the interpretative authority of the historian" (Uricchio, 2005, pp. 327-328). These historians argued that historical representations can never be "objective" but always will be present-day reconstructions. What traditional historians have called "objective" must be brought up for discussion. In addition, we need to put into question so-called authorities who claim the exclusive right to say what really happened. The computer games mentioned previously problematize the notions of "objectivity" and "authority," either to challenge them (CNN, Minister of Immigration) or to support them (Warren Rapport).

\section{SUBLIME HISTORICAL EXPERIENCE}

My affirmative answer, to the question of whether computer games can be considered documentary, is a dual one. I distinguish my argument from the pseudo-objectivity of the documentary as the representation of reality, and from the pseudo-subjectivity of its critics. When considering the arguments and counter-arguments mentioned here, I argue that documentary computer games are situated somewhere between both ends of the spectrum: They do not represent the historical reality objectively, but they are more than just subjective impressions of the artists involved.

For a better explanation of this specific position, I would like to turn briefly to a concept of the Dutch historian Frank Ankersmit (2005): the sublime historical experience. According to Ankersmit, both ends of the spectrum described here are disappointing because in their own way each of them excludes the notion of experience: "If you dispense with experience, you lack the intuition, openness and sus-

\footnotetext{
${ }^{15}$ The BBC (n.d.) Web site described Walking with Dinosaurs as follows: "Broadcast in 1999, Walking with Dinosaurs set out to create the most accurate portrayal of prehistoric animals ever seen on the screen. Combining fact and informed speculation with cutting-edge computer graphics and animatronics effects, the series took two years to make" (http://www.bbc.co.uk/sn/prehistoric_life/tv_radio/wwdinosaurs).

${ }^{16}$ It would be interesting to analyze the different forms of realism in gaming for their ability to function as indications of a switch to a documentarizing lecture. Galloway (2004) distinguished realistic narrative (The Sims), realistic representation (SOCOM Navy Seals [Zipper Interactive, 2002]), and social realism (Special Force [Hizbullah Central Internet Bureau, 2003] and Under Ash [Dar Al-Fikr, 2001]).
} 
ceptibility towards the knowable and, therefore, towards the past. That is the reason for my rehabilitation of experience as a source of insight" (as cited in Panhuysen, 2005, p. 43). Ankersmit connected the sublime experience with the experience of rupture, with dramatic events that cause changes: "These are the moments when present and past separate and the past is born as it were. 'The sublime' refers to the original meaning of the word when the pleasant and the terrible occur simultaneously" (Panhuysen, 2005, p. 43, author's translation).

The idea of the historical sublime seems to increase our understanding of what users experience when they play computer games such as JFK Reloaded and 9-11 Survivor that simulate traumatic events in U.S. history. In both games, players reenact experiences of rupture that separated the past and present in a traumatic way. These experiences are paradoxical in a sublime way in the sense that they, as experiences that transcend the individual level, ${ }^{17}$ involve and unite both the loss and pain of the trauma and, at the same time, the satisfaction of overcoming these feelings in terms of precognitive historical insights. This, however, does not free us from the question of whether these specific games are adequate stand-ins for lived experience. When it comes to the games described in this article no agreement has been reached on this point, as I have shown.

\section{PLEA IN FAVOR OF THE DOCUMENTARY GAME}

The four games I discuss in this article contain textual or contextual signs (or both) that justify a documentarizing lecture defining them as docu-games. When Renov (1993b) concluded that "It becomes very clear in the examination of the documentary film that the formal characteristics that define the cycles or styles of this film form (the actualité, cinépoem, or cinema vérité) are historically and ideologically contingent" (p. 19), there seems to be no reason to exclude games a priori from the category of the documentary form. This point of view makes even more sense when we take the poetics of the documentary into account. Renov described them as, "the four fundamental tendencies or rhetorical/aesthetic functions attributable to documentary practice ... 1. to record, reveal, or preserve; 2 . to persuade or promote; 3. to analyze or interrogate; 4. to express" (p. 21). These four discursive functions are, indeed, present in the games I discuss here, albeit in different forms: the preservation of the traumatic experience in 9-11 Survivor, the persuasion of the players of the inhuman conditions of immigration-detention centers in Escape from Woomera, the analysis of the assassination in JFK Reloaded, and the expression of the paradoxical position of David Koresh in Waco Resurrection.

\footnotetext{
${ }^{17}$ Henry Jenkins (2005) described computer games as "lively" works of art and as such these docu-games present players with the opportunity to experience something essential. Or in the words of the Dutch philosopher Henk Oosterling (2000), "The examples given are neither empirical evidence nor mere illustrations. They are-and here I am referring to Kant- exemplary ... Their exemplary quality makes them singular-universal"' (p. 15, author's translation).
} 
When looking at the issues gamers have brought up for discussion, for example on the Water Cooler Games forum, it struck me that they asked fundamental questions about the reliability of historical representation (JFK, the movie), simulation (JFK, the game), official information (e.g., the Warren Rapport), and details about detention centers (e.g., Woomera). When Renov (1993b) referred to the "impoverishment of a documentary film culture" (p. 20), games may offer what Renov was looking for; namely, "an energized climate of ideas and creative activities fueled by debate and public participation" (p. 20). Documentary computer games are capable of opening the area of the historical documentary to a large audience and may become very popular judging from the enthusiasm with which computer games generally are played and discussed. Whereas the documentary film has always tried to find stylistic as well as narrative ways to address spectators, gamers are immersed into experience and reenact historical events in interactive ways. Games are not only attractive because they please their users, but they could also turn out to be very effective in achieving such an educational effect.

If we prefer documentary computer games to really function in this way, designers have to pay attention to what Odin (1995b) called role adoption in the context of documentary films. A harmonious "space of communication" is only created if designer and player of the game adopt the same role, or as Odin called it "the same way of producing meaning and affects" (p. 227). Because the dominant communication regime in computer games is the "fictionalizing regime" (Odin, 1995b, p. 228), as is the case with film, documentary games run the same risk as documentary films; namely, of being "something we hardly have the desire to look at spontaneously, since it is often regarded as something that is fundamentally boring" (Odin, 1995b, p. 230). ${ }^{18}$ The public will only accept the documentary computer game if it creates something that could be described by the neologism "faction": the combination of "facticity" or "documentarity" with the pleasure derived from playing fictional computer games. One of the biggest challenges of game design is precisely this difficult task to create satis-faction: to harmoniously include "this documentarizing communication pact" into computer games and thereby go beyond fact and fiction.

\section{ACKNOWLEDGMENTS}

This article is written within the Utrecht Media Research program (see www.let.uu.nl/umr). I thank Frank Kessler for helpful comments on this article.

\footnotetext{
${ }^{18}$ On the Water Cooler Game forum, JFK Reloaded was criticized by one of the players for this reason: "I couldn't consider this a game unless you could improve upon or alter the events in any way, aside from timing, such as moving to a different position, or somehow creating a new chain of events. If I went to the store and bought a game only to find out I can do nothing but aim my gun and shoot 3 bullets in the same scenario over and over, I'd return it immediately ... that's not a game." In this case it is obvious that the space of communication was not created harmoniously.
} 


\section{REFERENCES}

Ankersmit, F. (2005). Sublime historical experience. Palo Alto, CA: Stanford University Press.

Auiler, D. (1998). Vertigo: The making of a Hitchcock classic. New York: St. Martin's Press.

Bazin, A. (1967). The ontology of the photographic image. In A. Bazin (Ed.), What is cinema? (pp. 9-16). Berkeley: University of California Press.

BBC. (n.d.). Walking with dinosaurs. Retrieved January 23, 2006, from http://www.bbc.co.uk/sn/prehistoric_life/tv_radio/wwdinosaurs/

Bolt, R. (2005). History play. London: Harper Perennial.

Carroll, N. (1996). Nonfiction film and postmodernist skepticism. In D. Bordwell \& N. Carroll (Eds.), Post-theory: Reconstructing film studies (pp. 283-306). Madison: The University of Wisconsin Press.

Ewing, K. (n.d.). JFK reloaded. Retrieved January 23, 2006, from http://www.jfkreloaded.com/

Frasca, G. (2004). Videogames of the oppressed: Critical thinking, education, tolerance, and other trivial issues. In N. Wardrip-Fruin \& P. Harrigan (Eds.), Firstperson: New media as story, performance, and game (pp. 85-94). Cambridge, MA: MIT Press.

Galloway, A. R. (2004). Social realism in gaming. Game Studies: The International Journal of Computer Game Research, 4(1). Retrieved from http://www.gamestudies.org.

Jenkins, H. (2005). Games, the new lively art. In J. Raessens \& J. Goldstein (Eds.), Handbook of computer game studies (pp. 175-192). Cambridge, MA: MIT Press.

Kattenbelt, C., \& Raessens, J. (2003). Computer games and the complexity of experience. In M. Copier \& J. Raessens (Eds.), Level up: Digital games research conference (pp. 420-425). Utrecht: Faculty of Arts, Utrecht University.

Kessler, F. (1998). Fakt oder fiktion? Zum pragmatischen Status dokumentarischer bilder [Fact or fiction? On the pragmatic status of documentary images]. In Montage/AV, 7/2/1998 (pp. 63-78). Marburg, Germany: Schüren Verlag.

Stone, O. (Director). (1991). JFK [Motion picture]. United States: Warner Brothers.

Odin, R. (1995a). For a semio-pragmatics of film. In W. Buckland (Ed.), The film spectator: From sign to mind (pp. 213-226). Amsterdam: Amsterdam University Press.

Odin, R. (1995b). A semio-pragmatic approach to the documentary film. In W. Buckland (Ed.), The film spectator: From sign to mind (pp. 227-235). Amsterdam: Amsterdam University Press.

Oosterling, H. (2000). Radicale middelmatigheid [Radical mediocracy]. Amsterdam: Boom.

Panhuysen, L. (2005, October 8 and 9). Het verleden laat zich niet kennen [You cannot know the past]. In NRC Handelsblad, p. 43.

Raessens, J. (2005). Computer games as participatory media culture. In J. Raessens \& J. Goldstein (Eds.), Handbook of computer game studies (pp. 373-388). Cambridge, MA: MIT Press.

Renov, M. (1993a). Introduction: The truth about non-fiction. In M. Renov (Ed.), Theorizing documentary (pp. 1-11). New York: Routledge.

Renov, M. (1993b). Towards a poetics of documentary. In M. Renov (Ed.), Theorizing documentary (pp. 12-36). New York: Routledge.

Turkle, S. (1996). Life on the screen: Identity in the age of the Internet. London: Weidenfeld \& Nicolson.

Uricchio, W. (2005). Simulation, history, and computer games. In J. Raessens \& J. Goldstein (Eds.), Handbook of computer game studies (pp. 327-338). Cambridge, MA: MIT Press.

Winston, B. (1993). The documentary film as scientific inscription. In M. Renov (Ed.), Theorizing documentary (pp. 37-57). New York: Routledge.

Winston, B. (1995). Claiming the real: The Griersonian documentary and its legitimations. London: BFI Publishing. 